\title{
The Critically Endangered Myanmar snub-nosed monkey Rhinopithecus strykeri found in the Salween River Basin, China
}

\author{
Yin Yang, Ying-Ping Tian, Chen-Xiang He, Zhipang Huang \\ Shao-Hua Dong, Bin Wang, Guang-Song Li, Zuo-Fu Xiang \\ YONG-CHENG LONG and WEN XIAO
}

\begin{abstract}
The Myanmar snub-nosed monkey Rhinopithecus strykeri was discovered in 2010 on the western slopes of the Gaoligong Mountains in the Irrawaddy River basin in Myanmar and subsequently in the same river basin in China, in 2011. Based on 2 years of surveying the remote and little disturbed forest of the Gaoligong Mountains National Nature Reserve in China, with outline transect sampling and infrared camera monitoring, a breeding group comprising $>70$ individuals was found on the eastern slopes of the Gaoligong Mountains in the Salween River Basin. Given the Critically Endangered status of this primate (a total of $<950$ individuals are estimated to remain in the wild), efforts to protect the relatively undisturbed habitat of this newly discovered population and to prevent hunting are essential for the long-term survival of this species.
\end{abstract}

Keywords China, Myanmar snub-nosed monkey, new population, Rhinopithecus strykeri, Salween River

he snub-nosed monkey genus Rhinopithecus was previ-
ously thought to comprise four rare, threatened pri-
mates ( $R$. avunculus, $R$. bieti, $R$. brelichi and $R$. roxellana),
known only from isolated parts of southern China and nor-
thern Vietnam (IUCN, 2016). Rhinopithecus strykeri, known
as the Myanmar snub-nosed monkey, or Nujiang snub-
nosed monkey in China, was discovered in 2010 in forests
above $1,720 \mathrm{~m}$ altitude in Kachin state, north-east
Myanmar (Geissmann et al., 2011). A second population

Yin Yang*, Zhipang Huang, Shao-Hua Dong $†$, Zuo-Fu Xiang $\ddagger$, Yong-Cheng LONG $\$$ (Corresponding author) and WeN XIAO (Corresponding author) Institute of Eastern-Himalaya Biodiversity Research, Dali University, Dali, Yunnan, 671003, P.R. China. E-mail YoNG-CheNG LoNG 445936671@qq.com; WEN XIAO xiaow@eastern-himalaya.cn

Ying-Ping Tian, Chen-Xiang He, Bin Wang and Guang-Song Li Lushui Bureau of Gaoligongshan National Nature Reserve, Liuku, Yunnan, P.R. China

*Also at: School of Archaeology and Anthropology, Australian National University, Canberra, Australia

$\dagger$ Also at: Lushui Bureau of Gaoligongshan National Nature Reserve, Liuku, Yunnan, P.R. China

$\ddagger$ Also at: Central South University of Forestry and Technology, Changsha, P.R China

$\S$ Also at: Sino-France Joint Lab for Wildlife Management \& Ecosystem Health, Yunnan Finance \& Economy University, Kunming, Yunnan, 650221, P.R. China

Received ${ }_{13}$ April 2016. Revision requested 21 July 2016.

Accepted 3 August 2016. First published online 28 November 2016. was discovered the following year in Pianma on the western slopes of Gaoligong Mountains, in Yunnan, China (Fig. 1; Long et al., 2012). Rhinopithecus strykeri primarily inhabits mid-montane moist evergreen broad-leaved forest and coniferous broad-leaved mixed forest (Geissmann et al., 2011; Chen et al., 2015). Genetic evidence indicates that it separated from the $R$. bieti clade in the Late Pleistocene, c. 0.24 million years ago (Liedigk et al., 2012) when two major barriers, the Mekong and the Salween Rivers, may have physically isolated segments of the parent population. All species of snub-nosed monkeys are reported to live in a multilevel or modular society, composed of several onemale harem breeding units that travel together to form a band, and one or more all-male units that follow the band (Kirkpatrick \& Grueter, 2010).

Interviews (Geissmann et al., 2011; Ma et al., 2014) suggested there may be up to 14 groups of Myanmar snubnosed monkeys, with a total population of $<950$ individuals, in four separate areas close to the Sino-Myanmar border: one in Pianma, China, and three in Myanmar. In China field observations of $R$. strykeri in Pianma have been conducted since 2011 (Chen et al., 2015), although limited behavioural data have been collected because of the rugged terrain and long rainy season from April to October. This group, with $>100$ individuals, lives at $2,400-3,300 \mathrm{~m}$ and has an estimated home range of $22.9 \mathrm{~km}^{2}$ (Chen et al., 2015).

Ma et al. (2014) predicted the species would also occur on the eastern slope of the Gaoligong Mountains, in China, where we searched during October 2013-September 2015 (see search area in Fig. 1). One or two researchers, with two field guides, searched for the species using outline transects (Plumptre et al., 2013) along each sub-ridge, during o8.00-19.00, 1-3 weeks per month depending on weather. We located the species, and took $>200$ photographs and 27 videos (Plate 1). We also found evidence of chewed branches and faeces consistent with those collected from the species at other sites.

In addition, we set up 19 camera traps (Acorn Ltl-6210 MC, Shenzhen Ltl Acorn Electronics, China) during April-September 2015, on wildlife trails and in five food trees, at a height of $15-20 \mathrm{~m}$. The trees were three toufucha Gamblea ciliata and two shanxiangguo Dodecadenia grandiflora, which were identified by our local guides as feeding trees for the species. We obtained 54 successive infrared 

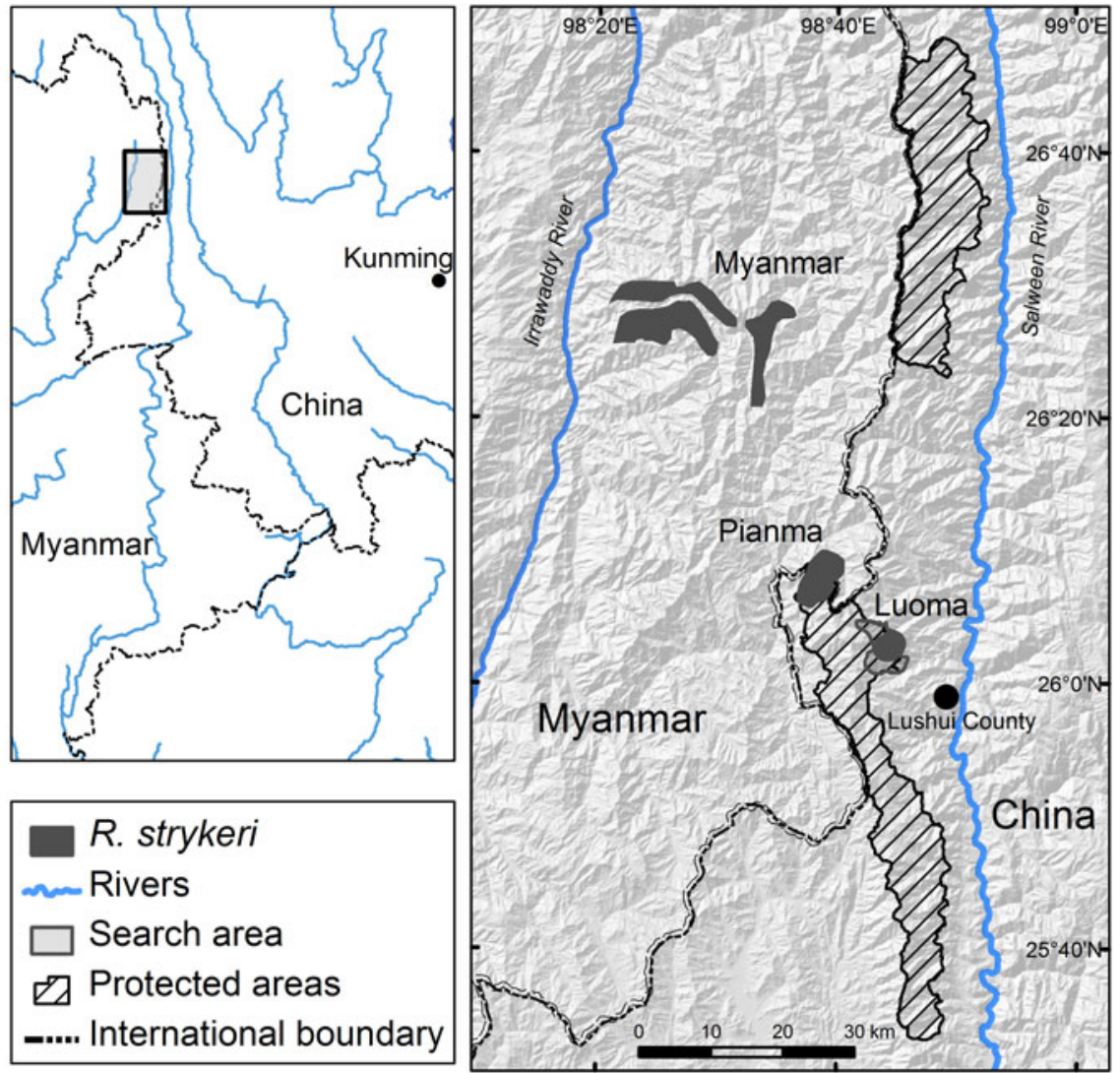

FIG. 1 Locations of the known populations of Rhinopithecus strykeri in the Sino-Myanmar border region. camera-trap photographs of the species in one event. The camera trap was in one of the toufucha tree crowns.

We collected faeces on 5 May 2015, at 3,180 m, and confirmed they were the faeces of Myanmar snub-nosed monkeys based upon their shape, size and contents, which included the remains of leaves and conifer needles. At 19.00 on 16 September 2015 we observed Myanmar snubnosed monkeys fighting and vocalizing loudly in a patch of hemlock Tsuga dumosa-bamboo-rhododendron forest; they then moved to a sleeping site on the ridge of the mountain at about 19.30. The next day we followed them during 7.00-16.30. We ceased to follow the group thereafter because of heavy rain and dense fog. We had followed the group for approximately $9 \frac{1}{2}$ hours, at a mean travel speed of $168.2 \mathrm{~m}$ per hour. Assuming that the group would have continued travelling and foraging for at least another $2^{1 / 2}$ hours, we estimate the snub-nosed monkeys would have travelled c. $2,018 \mathrm{~m}$ on that day.

To estimate group size we reviewed the 4 infrared photographs, identifying 18 adult or subadult monkeys, with 10 appearing in photographs during $17.53^{-17.58}$ and eight in photographs during 18.06-18.10. The mean passing rate of snub-nosed monkeys was 2.3 individuals per minute. Given that several distinguishable adult males appeared in these photographs, and none of the monkeys were carrying infants, we assume these individuals were members of an all-male unit. In addition, on one occasion we observed c. 20 infant and juvenile monkeys. Given the sex-age ratios of males to females (1:2.1), females to infants (4.7:1), and adults to immatures (2.5:1) in the Pianma $R$. strykeri population (Li et al., 2014), we tentatively estimate that this population comprises $>70$ individuals.

The Luoma population lies c. $14 \mathrm{~km}$ in a straight line south-east of the Pianma population reported by Long et al. (2012) and $80 \mathrm{~km}$ south-east of the Myanmar site reported by Geissmann et al. (2011). The Luoma population lives in the core zone of the Gaoligong Mountain National Nature Reserve, 1 day's walk from the nearest village. The forests are mostly mixed broad-leaf-hemlock forest or hemlock-rhododendron forest at 2,600-3,300 m, and are mostly pristine, with little anthropogenic disturbance. Compared to the declining populations in Myanmar (c. 300 individuals; Geissmann et al., 2011) and Pianma (c. 100 individuals; Chen et al., 2015), which have suffered from the threat of hunting and habitat degradation (Geissmann et al., 2011; Yin Yang, pers. obs.), the Luoma population may have potential to be a source population for the formation of new additional $R$. strykeri populations, and therefore requires strict and effective conservation management.

Additionally, living in forests dominated by hemlock, the ecology of the Luoma population may differ from that of the other populations, which inhabit moist evergreen broadleaved forests. Based on 358 interviews with local people in the region, individuals of this population may travel to forests 


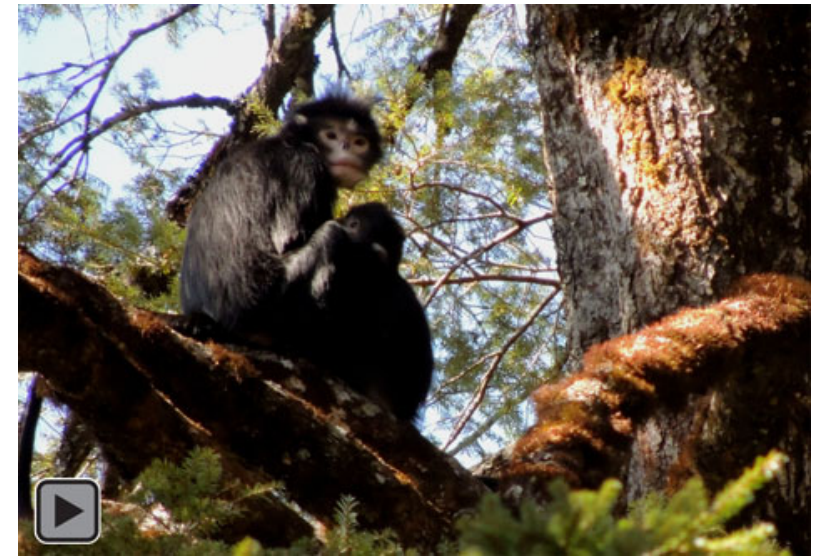

Plate 1 Mother and infant of Rhinopithecus strykeri in the newly discovered population in Luoma, China, near the border with Myanmar (Fig. 1).

outside the Reserve, close to Chengan township, where they may occasionally be hunted by the Lisu people (Ma et al., 2014). The border of the reserve may therefore need to be adjusted to ensure the full protection of the population. We aim to conduct further research and to develop a conservation action plan to protect nearby forests, which also harbour other threatened species, such as the Endangered red panda Ailurus fulgens styani, Vulnerable Mishmi takin Budorcas taxicolor taxicolor, and Vulnerable Sclater's monal Lophophorus sclateri. In addition, further surveys to locate other potential R. strykeri populations and to determine accurately the population size in the Sino-Myanmar region are required for a full assessment of the conservation status and needs of this Critically Endangered primate.

\section{Acknowledgements}

This research complied with the regulations governing primate research in China, and the policies and guidelines of the Australian National University and Dali University for the ethical treatment of primates. We thank the Nujiang Forestry Department and the Gaoligong Mountain Nature Reserve for their support during our surveys. Our field guides, Afenghua and Kenhuaniuba, contributed to this study. Paul A. Garber, Colin Groves, Guy Michael Williams and two anonymous reviewers provided valuable suggestions and helped with English. This research was funded by the National Science Foundation of China (31260149, 31260145, 31670397) and Zoological Society for the Conservation of Species and Populations (Germany; 7.Rhinopithecus. MMR.2015), and also supported by the Collaborative Innovation Centre for Biodiversity and Conservation in the Three Parallel Rivers Region of China and Key Lab of Yunnan Education Department in Erhai Catchment Biodiversity Conservation and Sustainable Development.

\section{Author contributions}

YY, Y-CL and WX conceived the research. C-XH, BW and G-SL facilitated the field work. YY, Y-PT, C-XH, ZH, S-HD, BW and G-SL led the long-term field research. YY, Y-PT, $\mathrm{ZH}$ and S-HD performed the analyses and mapping. YY wrote the article with input from Y-CL, Z-FX and WX.

\section{References}

Chen, Y., Xiang, Z., Wang, X., Xiao, W., Xiao, Z., Ren, B. et al. (2015) Preliminary study of the newly discovered primate species Rhinopithecus strykeri at Pianma, Yunnan, China using infrared camera traps. International Journal of Primatology, 36, 679-690.

Geissmann, T., Lwin, N., Aung, S.S., Aung, T.N., Aung, Z.M., Hla, T.H. et al. (2011) A new species of snub nosed monkey, genus Rhinopithecus Milne-Edwards, 1872 (Primates, Colobinae), from northern Kachin State, northeastern Myanmar. American Journal of Primatology, 73, 96-107.

IUCN (2016) The IUCN Red List of Threatened Species v. 2016.1. Http:// www.iucnredlist.org [accessed 21 July 2016].

Kirkpatrick, R.C. \& Grueter, C.C. (2010) Snub-nosed monkeys: multilevel societies across varied environments. Evolutionary Anthropology: Issues, News, and Reviews, 19, 98-113.

Li, G.S., Chen, Y.X., Sun, W.M., Wang, X.W., Huang, Z.P., Li, Y.P. et al. (2014) Preliminary observation of population status and social organization of Rhinopithecus strykeri in Pianma Town, Nujiang County, China. Acta Theriologica Sinica, 34, 323-328. [In Chinese]

Liedigk, R., Yang, M., Jablonski, N.G., MomberG, F., Geissmann, T., Lwin, N. et al. (2012) Evolutionary history of the odd-nosed monkeys and the phylogenetic position of the newly described Myanmar snub-nosed monkey Rhinopithecus strykeri. PLoS ONE, 7(5), e37418.

LonG, Y., Momberg, F., MA, J., Wang, Y., Luo, Y., Li, H. et al. (2012) Rhinopithecus strykeri found in China! American Journal of Primatology, 74, 871-873.

Ma, C., Huang, Z., Zhao, X., Zhang, L., Sun, W., Matthew, S. et al. (2014) Distribution and conservation status of Rhinopithecus strykeri in China. Primates, 55, 377-382.

Plumptre, A.J., Sterling, E.J. \& Buckland, S.T. (2013) Primate census and survey techniques. In Primate Ecology and Consevation: A Handbook of Techniques (eds E.J. Sterling, N. Bynum \& M. E. Blair), pp. 13-18. Oxford University Press, Oxford, UK.

\section{Biographical sketches}

YIN YANG is studying the behaviour and conservation biology of $R$. strykeri in the Gaoligong Mountains National Nature Reserve in China. YING-PING TIAN is a park ranger committed to the conservation of R. strykeri. CHEN-XIANG He, BIN WANG and GUAN-Song LI are governors of the reserve and initiated the conservation programme for $R$. strykeri in China. SH A O-Hu A Dong has coordinated field surveys for R. strykeri. ZH I A A G HU ANG's research interests include conservation biology and the behavioural ecology of primates. ZU o-Fu XI A G specializes in the conservation biology, behaviour and cognitive science of primates. YONG - CHENG LONG is a primatologist with a lifelong interest in snub-nosed monkeys. WEN XIAO has a wide range of research interests in conservation biology, behavioural ecology and wildlife-habitat relationships, especially of primates. 